\section{Antenatal screening for Down's syndrome}

EDrToR,-Nicholas J Wald and colleagues' demonstration project' implies that there is nothing left to prove with regard to the "triple test" screening of pregnant women for Down's syndrome, and that all that remains is for the test to be introduced on a national level immediately. This is a premise I and others feel unhappy about, as recent correspondence has shown. ${ }^{2}$

Wald and colleagues report the results of screening 12603 women with the triple test, achieving a detection rate of $48 \%$ in that population. It is true that the numbers are small $(12 / 25)$, but this is considerably below the $58 \%$ previously suggested. The paper does not refer at all to the $26 \%$ of women not screened. If the 12603 women discussed in the paper were the $74 \%$ who had the blood test, the total population under study therefore comprised 17031 women. Because we have no information about the demographic characteristics of the other 4428 women, or the outcomes of their pregnancies, I can only assume that the rate of Down's syndrome in their pregnancies was the same as in the screened population. Thus, the conclusion must be that some 34 pregnancies in the study population were affected with Down's syndrome. This figure reduces the detection rate for this pregnant population as a whole to $35.3 \%$ and the known prevention of Down's births (presumably the desired outcome) to $26.5 \%$. Additionally, a two way table for the screened population gives the triple test a positive predictive value of only $2 \cdot 3 \%$, a figure well below that required for any method of screening.

On this basis, it must again be asked whether the wholesale introduction of triple test screening is either appropriate or effective. Wald and colleagues' paper certainly does not show, despite its claims, that the incidence of Down's births will be reduced much further in practice. It is probable that the psychological costs of this programme to pregnant women will be enormous': 17031 had to consider the test, 12603 had to wait for results, and 514 undergo amniocentesis. We are not told the miscarriage rate. It also seems from recent correspondence ${ }^{67}$ that the costings used by the authors for their cost effectiveness analysis are probably an underestimate. As there are costs incurred through counselling for all women, the cost effectiveness analysis looks even less favourable when the whole population, rather than only those who are screened, is considered.

Department of Public Health Medicine,

South West Surrey Health Authority,

Guildford,

Surrey GU2 5LX

1 Wald NJ, Kennard A, Densem JW, Cuckle HS, Chard T, Butle L. Antenatal maternal serum screening for Down's syndrome: results of a demonstration project. BMF 1992;305:391-4. (15 August.)

\section{Advice to authors}

Priority will be given to letters that are less than 400 words long and are typed with double spacing. All authors should sign the letter. Please enclose a stamped addressed envelope for acknowledgment.
2 Fleming C, Goldie DJ. Risk of Down's syndrome and amniocentesis rate. $B M \mathcal{F}^{1992 ; 304: 252}$.

3 Keatinge RM, Williams ES. Screening for Down's syndrome. BMF 1991;303:1063.

4 Wald NJ, Cuckle HS, Densem JW, Kennard A, Smith D Maternal serum screening for Down's syndrome: the effect of routine ultrasound scan determination of gestational age and adjustment for maternal weight. Br f Obstet Gynaecol 1991;99: 144-9.

5 Marteau T. Reducing the psychological costs. BMF 1990;303 26-8.

6 Keatinge RM, Williams ES. Prenatal screening for Down's syndrome. BMF 1991;303:54

7 Davies T, Kha OS. Prenatal screening for Down's syndrome BMf 1991;303:312

EdITOR,-Nicholas J Wald and colleagues conclude that antenatal maternal serum screening is cost effective and that the NHS should ensure its availability throughout Britain.' Their results do not support this contention. Screening detected only $12(48 \%)$ of the 25 affected pregnancies and led to abortion in only $9(36 \%)$. Even less impressive is the detection rate of $39 \%$ in women aged under 37 , in whom most affected pregnancies occur. For each woman with a "positive" screening result the odds of having an affected fetus were 1 in 43 , and for each woman having amniocentesis the odds were 1 in 29 . The positive predictive value is $1.6 \%$ before and $2 \cdot 3 \%$ after revision of dates by ultrasound examination. Would such results be acceptable for other screening programmes, such as mammography followed by biopsy for breast cancer?

The claim that screening is cost effective is based solely on an estimate of financial costs. There is no mention of the costs to women in terms of repeated clinic visits, morbidity and miscarriage after amniocentesis, and anxiety while waiting several weeks from the initial screening to receive the results of karyotyping. There is no confirmation that all aborted fetuses had Down's syndrome. There is also no discussion of the finding that the level of risk had only a small influence on the decision of $25 \%$ of women with a "positive" screening result not to have amniocentesis.

Finally, the authors write that "the predicted results are a better guide to expected performance than the observed results in this dataset would indicate." The logical conclusion of such a statement is that the results of research should be ignored if they fail to come up to the authors' expectations.

Department of Public Health Medicine,

West Berkshire Health Authority,

Reading RG3 4EJ

1 Wald NJ, Kennard A, Densem JW, Cuckle HS, Chard T, Butler L. Antenatal maternal screening for Down's syndrome: results L. Antenatal maternal screening for Down's syndrome: results
of a demonstration project. BMF 1992;305:391-4. (15 August.)

EDITOR,-International leadership in prenatal screening resides in Britain; accordingly British public health policy has positively influenced other nations. Against that background, Nicholas J Wald and colleagues call for the establishment of British policy to achieve "the avoidance of handicap . . . to families." When the work of some scientists and medical professors concludes with nationally directive pronouncements-for example, "the NHS should ensure that antenata maternal serum screening for Down's syndrome is available throughout Britain," others may wish to consider whether the underlying data reasonably support the conclusions. We find Wald and colleagues' national expectations to be costly, the data unconvincing, and the conclusions premature.

We urge that more information be obtained because the costs per affected case are underestimated; the utility of unconjugated oestriol as a third marker is not reported; Wald and colleagues' reported detection rates ( $48 \%$ overall, $39 \%$ for the screening population under 37 years of age) are lower than detection rates using other assay protocols; and independent reports on false positive rates and detection efficiency should be obtained from other screening centres.

Wald and colleagues use $61 \%$ detection in estimating costs rather than their published detection rate of $48 \%$. At $48 \%$ (even without accounting for the cost of maternal serum $\alpha$ fetoprotein measurements) the public sector direct cost per detected affected pregnancy is $£ 36256$, not $£ 28500$ (assuming 100\% uptake of amniocentesis and $100 \%$ termination of affected pregnancies). The cost increases to $£ 48780$ with $75 \%$ uptake of amniocentesis and $90 \%$ termination of affected pregnancies. Considering private sector triple test costs at $£ 60$ per test ${ }^{2}$ and an incidence of 1.05 Down's syndrome cases per 1000 live births in Britain, ${ }^{3}$ the costs increase to $£ 134929$ and $£ 174511$ respectively.

The authors omit showing how using unconjugated oestriol in an assay protocol affects detection and false positive rates despite published studies showing negative impact. ${ }^{4}$ They should responsibly show that each biochemical marker improves on Down's syndrome screening detection rates.

Reported detection rates with other assay proto cols are $89 \%,{ }^{5} 80 \%,{ }^{6} 78 \%,{ }^{7} 75 \%$ (R.G Ryall, personal communication). Laboratories currently using the triple test and the " $\alpha$ lpha" software should publish their independently observed data on detection and false positive rates so that doctors and scientists may accurately gauge effectiveness and give the NHS a clearer statement of the facts.

VINCENT J MACRI REBECCA CLARK

NTD Laboratories,

Carle Place, New York 11514-2137

USA

1 Wald NJ, Kennard A, Densem JW, Cuckle HS, Chard T, Butle L. Antenatal maternal serum screening for Down's syndrome: results of a demonstration project. BMF 1992;305:391-4. (15 August.)

2 Ballantyne A. Mother sues over lack of Down's test. Sunday Times 1992 August 23:4.

Sheldon TA, Simpson J. Appraisal of a new scheme for prenatal screening for Down's syndrome. BMF 1991;302:1133-6.

4 Macri JN, Cook EJ, Kasturi RV, Krantz DA. Prenatal screening for Down's syndrome. BMF 1 1991;303:468.

for Down's syndrome. BMf 1991;303:468.
5 Spencer K, Carpenter P. Risk of Down's syndrome and amnioSpencer K, Carpenter P. Risk of Down's synd
centesis. BMf 1992;304:640-1. (7 March.)

6 Macri JN, Kasturi RV, Krantz DA, Cook EJ, Moore ND, Young $\mathrm{JA}$, et al. Maternal serum Down syndrome screening: free $\beta$ $\mathrm{JA}$, et al. Maternal serum Down syndrome screening: free $\beta$ protein is a more effective marker than human
gonadotropin. Am $\mathcal{F}$ Obstet Gynecol 1990;163:1248-53.

7 gonadotropin. Am $\mathcal{F}$ Obstet Gynecol 1990;163:1248-53. free beta human choriogonadotropin. Ann Clin Biochem 1992, 29:349-50.

EDITOR,-The results from the study by Nicholas $\mathrm{J}$ Wald and colleagues ${ }^{1}$ raise several important issues.

The implied conclusion that this form of Down's syndrome screening is more "effective" than screening by maternal age alone is debatable, as the findings could have occurred by chance. In the 